\section{Relation between cartilage loss and pain in knee osteoarthritis}

We read with interest the recent work in Annals of the Rheumatic Diseases by Bacon and colleagues regarding the relationship between cartilage loss and pain in patients with knee osteoarthritis (OA). ${ }^{1}$ The authors included 600 participants within the Osteoarthritis Initiative and found that cartilage loss was significantly associated with a small degree of worsening in pain over 24 months. The relation between cartilage thickness loss and pain was partially mediated by synovitis change, rather than by changes in bone marrow lesions. This finding prompted us to reconsider the relation between cartilage loss and pain, and the clinical efficacy of the chondroprotective application in the treatment of knee OA. Their excellent and important work adds to our knowledge base, but we do have two minor points that may help to contextualise findings from this study and contribute to further investigations.

First, the predominant patient population included in this study was mild to moderate OA by Kellgren-Lawrence (K\&L) grade, which is the typical population in whom chondroprotective agents are indicated. ${ }^{2}$ However, in this study, neither patients with severe OA (K\&L grade 4) were included, ${ }^{3}$ nor subanalysis based on the $\mathrm{K} \& \mathrm{~L}$ grade was performed. As OA-related knee pain usually becomes more severe over time, ${ }^{4}$ it is conceivable that there might exist a cumulative effect that the weak association of cartilage loss with pain could be stronger along the degenerative process of the knee (figure 1). Therefore, it remains unclear whether there exists a dose-response relationship between cartilage loss and pain worsening, and further studies are warranted to investigate if there was a dynamic association between cartilage loss and knee pain during the degenerative process.

Second, the robustness of the results and the conclusion is severely biased by using the Western Ontario and McMaster Universities Osteoarthritis Index (WOMAC) pain score as the outcome. Although the WOMAC pain scale is a well-established, validated instrument to measure the pain level during specific activities that likely to cause OA pain, ${ }^{1}$ it only provides a summary of temporal or short-term pain severity, while the duration of pain is ignored. Considering the knee pain in $\mathrm{OA}$ is chronic, intermittent, activity related and varies over time, ${ }^{4}$ the WOMAC pain scale is not an ideal assessment tool to analyse the relationship between cartilage loss and knee pain, even if WOMAC pain scale has been widely used in similar studies. ${ }^{5-7}$ Thus, the findings should be interpreted with caution, and chronic pain assessment tools ${ }^{8-10}$ should be adopted to accurately and continuously measure the pain intensity and pain

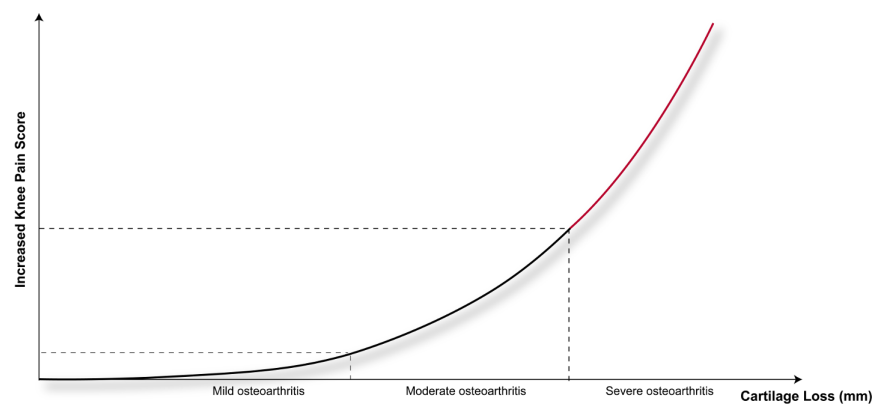

Figure 1 The possible dose-response relationship between cartilage loss and knee pain in osteoarthritis. Compared with patients with mild to moderate knee osteoarthritis, a loss of $0.1 \mathrm{~mm}$ of cartilage thickness in patients with severe knee osteoarthritis may associated with a higher increased knee pain score. duration. If the continuous knee pain was cumulatively calculated, we could understand exactly how or to what extent the loss of cartilage thickness is associated with knee pain in OA.

Xiang-Dong Wu $\odot,{ }^{1}$ Di Wu, ${ }^{1}$ Wei Huang $\odot ~,{ }^{2}$ Gui-Xing Qiu $\odot{ }^{1}$

${ }^{1}$ Department of Orthopaedic Surgery, Peking Union Medical College Hospital, Chinese Academy of Medical Sciences \& Peking Union Medical College, Beijing, China

${ }^{2}$ Department of Orthopaedic Surgery, The First Affiliated Hospital of Chongqing Medical University, Chongqing, China

Correspondence to Dr Gui-Xing Qiu, Department of Orthopaedic Surgery, Peking Union Medical College Hospital, Chinese Academy of Medical Sciences \& Peking Union Medical College, Beijing 100730, China; qiuguixing_pumch@126.com

Contributors XDW, DW, WH and GXQ contributed substantially to conception and design; drafted the article; gave final approval of the version to be published; and agreed to act as guarantors of the work.

Funding The authors have not declared a specific grant for this research from any funding agency in the public, commercial or not-for-profit sectors.

Competing interests None declared.

Patient and public involvement Patients and/or the public were not involved in the design, or conduct, or reporting, or dissemination plans of this research.

Patient consent for publication Not required.

Provenance and peer review Not commissioned; internally peer reviewed.

(c) Author(s) (or their employer(s)) 2020. No commercial re-use. See rights and permissions. Published by BMJ.

X-DW and DW contributed equally.

$$
\text { Check for updates }
$$

To cite Wu X-D, Wu D, Huang W, et al. Ann Rheum Dis Epub ahead of print: [please include Day Month Year]. doi:10.1136/annrheumdis-2020-218433

Received 25 June 2020

Accepted 27 June 2020

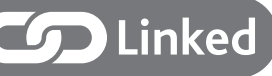

- https://doi.org/10.1136/annrheumdis-2020-218178

Ann Rheum Dis 2020;0:1. doi:10.1136/annrheumdis-2020-218433

\section{ORCID iDs}

Xiang-Dong Wu http://orcid.org/0000-0002-3920-4372

Wei Huang http://orcid.org/0000-0002-8894-0982

Gui-Xing Qiu http://orcid.org/0000-0001-7137-1843

\section{REFERENCES}

1 Bacon K, LaValley MP, Jafarzadeh SR, et al. Does cartilage loss cause pain in osteoarthritis and if so, how much? Ann Rheum Dis 2020. doi:10.1136/ annrheumdis-2020-217363. [Epub ahead of print: 07 May 2020].

2 Gallagher B, Tjoumakaris FP, Harwood MI, et al. Chondroprotection and the prevention of osteoarthritis progression of the knee: a systematic review of treatment agents. Am J Sports Med 2015;43:734-44.

3 Kohn MD, Sassoon AA, Fernando ND. Classifications in brief: Kellgren-Lawrence classification of osteoarthritis. Clin Orthop Relat Res 2016:474:1886-93.

4 Neogi T. The epidemiology and impact of pain in osteoarthritis. Osteoarthritis Cartilage 2013:21:1145-53.

5 Wluka AE, Wolfe R, Stuckey $S$, et al. How does tibial cartilage volume relate to symptoms in subjects with knee osteoarthritis? Ann Rheum Dis 2004;63:264-8.

6 Baum T, Joseph GB, Arulanandan A, et al. Association of magnetic resonance imagingbased knee cartilage T2 measurements and focal knee lesions with knee pain: data from the osteoarthritis initiative. Arthritis Care Res 2012;64:248-55.

7 Eckstein F, Collins JE, Nevitt MC, et al. Brief report: cartilage thickness change as an imaging biomarker of knee osteoarthritis progression: data from the foundation for the National Institutes of health osteoarthritis biomarkers Consortium. Arthritis Rheumatol 2015:67:3184-9.

8 Dansie EJ, Turk DC. Assessment of patients with chronic pain. Br J Anaesth 2013;111:19-25.

9 Fillingim RB, Loeser JD, Baron R, et al. Assessment of chronic pain: domains, methods, and mechanisms. J Pain 2016;17:T10-20.

10 van Wijk AJ, Lobbezoo F, Hoogstraten J. Reliability and validity of a continuous pain registration procedure. Eur J Pain 2013;17:394-401. 